\title{
Correcting reflux laparoscopically
}

\author{
Eric C Poulin MD FRCSC, Christopher M Schlachta MD FRCSC, Joseph Mamazza MD FRCSC
}

\begin{abstract}
EC Poulin, CM Schlachta, J Mamazza. Correcting reflux laparoscopically. Can J Gastroenterol 1998;12(5):327-332. Most operations in the abdominal cavity and chest can be performed using minimally invasive techniques. As yet it has not been determined which laparoscopic procedures are preferable to the same operations done through conventional laparotomy. However, most surgeons who have completed the learning curves of these procedures believe that most minimally invasive techniques will be scientifically recognized soon. The evolution, validation and justification of advanced laparoscopic surgical methods seem inevitable. Most believe that the trend towards procedures that minimize or eliminate the trauma of surgery while adhering to accepted surgical principles is irreversible. The functional results of laparoscopic antireflux surgery in the seven years since its inception have been virtually identical to the success curves generated with open fundoplication in past years. Furthermore, overall patient outcomes with laparoscopic procedures have been superior to outcomes with the traditional approach. Success is determined by patient selection and operative technique. Patient evaluation should include esophagogastroduodenoscopy, barium swallow, $24 \mathrm{~h} \mathrm{pH}$ study and esophageal motility study. Gastric emptying also should be evaluated. Patients who have abnormal propulsion in the esophagus should not receive a complete fundoplication (Nissen) because it adds a factor of obstruction. Dor or Toupet procedures are adequate alternatives. Prokinetic agents, dilation or pyloroplasty are used for pyloric obstruction ranging from little to more severe. Correcting reflux laparoscopically is more difficult in patients with obesity, peptic strictures, paraesophageal hernias, short esophagus, or a history of previous upper abdominal or antireflux surgery.
\end{abstract}

Key Words: Gastroesophageal reflux disease, Laparoscopic surgery, Minimally invasive techniques

\section{Correction laparoscopique du reflux}

RÉSUMÉ : La plupart des opérations à la cavité abdominale et au thorax peuvent être effectuées au moyen de techniques minimalement vulnérantes. Jusqu'à présent, on n’a pas déterminé que les techniques laparoscopiques étaient préférables à la même intervention effectuée par laparotomie classique. Toutefois, la plupart des chirurgiens qui se sont familiarisés avec ces interventions estiment que les techniques minimalement vulnérantes seront scientifiquement reconnues bientôt. L'évolution, la validation et la justification des méthodes chirurgicales laparoscopiques de pointe semblent inévitables. La plupart croient que la tendance en faveur d'interventions qui minimisent ou éliminent le traumatisme de la chirurgie tout en répondant aux principes chirurgicaux acceptés est irréversible. Les résultats fonctionnels de la chirurgie antireflux par laparoscopie enregistrés au cours de ses sept années d'existence ont été pour ainsi dire identiques aux taux de réussite enregistrés avec la fundoplication ouverte des années antérieures. De plus, les résultats globaux enregistrés chez les patients à l'aide des techniques laparoscopiques ont été supérieurs aux résultats des approches classiques. Le succès dépend de la sélection des patients et de la technique chirurgicale. L'évaluation des patients doit inclure une œsophago-gastro-duodénoscopie, un repas baryté, un dosage du pH sur 24 heures et une épreuve de motilité œesophagienne. La vidange gastrique doit également être évaluée. Les patients qui présentent une propulsion anormale au niveau de l'œsophage ne doivent pas subir de fundoplication totale (Nissen), car elle risque d'ajouter un facteur d'obstruction. Les interventions de Dor et de Touper sont de bonnes solutions de rechange. Les agents procinétiques, la dilatation ou la pyloroplastie seront utilisés dans les cas d'obstruction pylorique de légère à grave. La correction laparoscopique du reflux est plus difficile chez les patients atteints d'obésité, de strictures gastro-duodénales, d'hernies para-œesophagiennes, ou ayant un œsophage court ou encore des antécédents de chirurgie abdominale haute ou encore de chirurgie antireflux.

Department of Surgery, St Michael's Hospital, Wellesley Central Site, University of Toronto, Toronto, Ontario

Correspondence and reprints: Dr Eric C Poulin, Surgeon-in-Chief, The Wellesley Central Hospital, University of Toronto, 217B Jones

Building, 160 Wellesley Street, Toronto, Ontario M4Y 1J3. Telephone 416-926-7675, fax 416-944-8975 
$\mathrm{G}^{\mathrm{a}}$ astroesophageal reflux disease (GERD) accounts for $75 \%$ of esophageal pathology. At least $\$ 10$ billion is spent annually on prescription drugs for heartburn and dyspepsia, approximately twice the annual expenditure for gallstone treatment (1). Despite its frequency, GERD can be one of the most challenging diagnostic and therapeutic problems in benign esophageal disease. Although many patients are helped by changes in lifestyle and by intermittent or regular medication, others require surgery (2). Proper selection of patients for surgery is critical if good results are expected.

\section{FIVE REQUIREMENTS OF SURGICAL APPROACH TO GERD}

When surgery is considered, the evaluation of a patient with GERD requires the definition of five areas: GERD as the cause of the patient's symptoms; the severity of GERD; the underlying cause of GERD in the individual patient; which patients should undergo a surgical antireflux procedure; and the appropriate antireflux procedure.

Diagnosis: Simple reliance on patient symptoms is inadequate to diagnose GERD and select patients for surgery. Epigastric and retrosternal symptoms are common and nonspecific, and can signify a variety of conditions, including coronary artery disease, esophageal carcinoma, peptic ulcer disease, cholelithiasis, choledocholithiasis, chronic pancreatitis, diffuse esophageal spasm and achalasia $(3,4)$. Frequently GERD is associated with respiratory tract symptoms, including hoarseness, chronic cough, asthma and chest pain (5).

Reliance on the presence of esophagitis diagnosed at endoscopy to establish a diagnosis of GERD also has some drawbacks because $40 \%$ of patients with confirmed reflux causing their symptoms have no esophagitis at esophagogastroduodenoscopy, and in $10 \%$ of patients, esophagitis results from another cause (eg, chemical injury or drug ingestion) (6).

Properly defined GERD requires abnormal exposure of the esophagus to gastric juice. The best way to characterize the presence of disease and allow identification of the probable cause is $24 \mathrm{~h}$ ambulatory $\mathrm{pH}$ monitoring and esophageal manometry (7) (Table 1).

Indications for testing: Not all patients who have symptoms suggestive of GERD should undergo comprehensive testing. It is reasonable to treat unstudied patients for four weeks. Symptomatic treatment consisting of lifestyle changes, diet modification and acid reduction therapy with $\mathrm{H}_{2}$ blockers or omeprazole is the norm.

All patients who have persistent symptoms should undergo endoscopy and biopsy to rule out complications of GERD (esophagitis, stricture and Barrett's esophagus). This subset of patients is treated for an additional 12 weeks of acid suppression therapy, which is then stopped. More extensive esophageal function tests should be considered for patients who remain symptomatic, prove to be medicationdependent, fail to heal, and develop or fail to resolve complications while on therapy.

Preoperative testing: Most surgeons today do not consider surgery without $24 \mathrm{~h} \mathrm{pH}$ testing and esophageal manometry
TABLE 1

\section{Interpretation of reflux investigation}

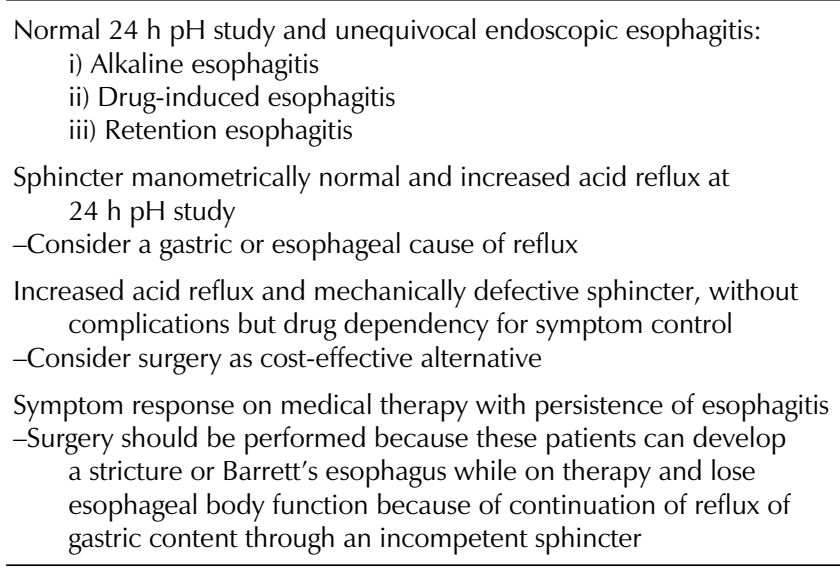

$(8,9)$. These are the most specific and sensitive tests widely available for the evaluation of GERD, and they help to confirm the diagnosis and determine the severity of the disease. In about $5 \%$ of patients, this evaluation determines that GERD is not the cause of the patient's symptoms and the investigation is reoriented. In $10 \%$ to $15 \%$ of patients, preoperative testing defines mild disease with a modest alteration of total reflux time or Demeester score. The treating physician then optimizes medication control while addressing lifestyle concerns more aggressively (eg, diet modification, weight control, smoking cessation and stress reduction). Perdikis et al (10) conducted an exercise where a panel of gastroenterologists and surgeons were presented basic clinical data from GERD patients and asked to make a treatment decision. After one month, either $24 \mathrm{~h} \mathrm{pH}$ study or manometry was added, and a further decision requested. Finally, the basic data, $24 \mathrm{pH}$ study and manometry were presented, and a decision was requested. Overall, $43 \%$ of decisions were altered by the addition of both manometry and $24 \mathrm{~h} \mathrm{pH}$ study (10).

Furthermore, adequate preoperative testing permits an appropriate choice of surgical procedure, determined largely by the propulsive ability of the esophagus and adequate gastric emptying. Preoperative testing also serves as a baseline study and permits better evaluation of patients with adverse results postoperatively $(3,7)$.

Mapping the strategy of antireflux surgery: Conceptually, the antireflux mechanism should be viewed as comprising three components: the lower esophageal sphincter, which acts as a valve between the stomach and the esophagus; the esophageal body, which serves as a pump to clear gastric reflux; and the stomach, which acts as a reservoir of the acidic gastric content. It also must be determined that the stomach empties adequately.

Because antireflux corrects only the functionally defective lower esophageal sphincter, it is important not only to localize the problem to the lower esophageal sphincter, but also to exclude abnormalities in the esophageal body and gastric reservoir. Many patients have abnormalities in the clearance of physiological reflux caused by a defective body 
of the esophagus or increased acid exposure of the lower esophagus because of gastroparesis, gastric dilation or delayed gastric emptying secondary to pyloric stenosis. Surgery directed only at reconstruction of an incompetent valve may worsen the symptoms in these patients.

Choice of surgical procedure: A number of factors must be considered before a final choice is made as to the best surgical approach.

The propulsive force of the body of the esophagus: It must be determined by esophageal manometry whether the esophagus has sufficient power to propel a bolus of food through a reconstructed lower esophageal sphincter. Patients who have normal contractions have good results with a $360^{\circ}$ wrap (Nissen fundoplication). Other procedures should be considered when peristalsis is absent, severely disordered or of low magnitude (less than $20 \mathrm{mmHg}$ ). The most frequently used alternatives performed laparoscopically are the Toupet procedure, a $270^{\circ}$ wrap or a so-called 'loose Nissen'. Some authors think that a normal Nissen wrap under these circumstance can create further obstruction to esophageal clearance and produce complications such as dysphagia, stasis ulcer and esophagitis.

Anatomical shortening of the esophagus: Anatomical shortening of the esophagus can create tension and either breakdown of a standard repair or migration of the repair into the chest. Shortening is identified radiologically by a sliding hernia that is not reduced in the upright position or that measures longer than $5 \mathrm{~cm}$ between the diaphragmatic crura and the gastroesophageal junction endoscopically. In such cases, esophageal lengthening procedures must be considered (Collis Nissen gastroplasty). The feasibility of performing this procedure using minimally invasive techniques was recently described (11).

Gastric hypersecretion and delayed gastric emptying: Under some circumstances, pyloric dilation, pyloroplasty and parietal cell vagotomy may be required with antireflux surgery.

\section{SURGICAL PRINCIPLES OF ANTIREFLUX SURGERY}

To reestablish cardial competence safely and maintain the patient's ability to swallow normally, the surgeon should adhere to a number of principles for good postoperative results.

First, the distal esophageal sphincter pressure must be restored. This value should be twice that of the resting gastric pressure (ie, $14 \mathrm{mmHg}$ for a gastric pressure of $7 \mathrm{mmHg}$ ). This is achieved by buttressing the distal esophagus with the fundus of the stomach. Improvement of postoperative pressure has been shown to be a function of the degree of gastric wrap around the esophagus.

Second, an adequate length (at least $3 \mathrm{~cm}$ ) of the distal esophagus must be placed in the positive pressure environment of the abdomen. The creation of a conduit that will ensure the transmission of intra-abdominal pressure changes around the abdominal portion of the sphincter is a necessary aspect of surgical repair.

Third, the reconstructed cardia should be allowed to relax on deglutition. To achieve this, only the fundus of the stomach should be used to buttress the sphincter, because it is known to relax in concert with the sphincter. In normal swallowing, a vagally mediated relaxation of the distal esophageal sphincter and the fundus occurs for about $10 \mathrm{~s}$. Then the gastric wrap must be placed around the sphincter and should not incorporate a portion of the stomach or be placed around the stomach because the body of the stomach does not relax with swallowing. Finally, it is imperative that the vagal nerves not be damaged during dissection of the esophagus.

Fourth, the fundoplication should not create resistance that exceeds the peristaltic power of the body of the esophagus. The resistance of the relaxed sphincter depends on the degree, length and diameter of the fundic wrap and on the variation of intra-abdominal pressure. To ensure minimal resistance of the relaxed sphincter, a $360^{\circ}$ wrap should not be longer than 2 or $3 \mathrm{~cm}$ and should be constructed over a large calibration bougie.

Finally, the fundoplication should be maintained intraabdominally without tension. Crural repair above the fundoplication and avoidance of tension prevent recurrence. A fundoplication in the thorax converts a sliding hernia into a paraesophageal hernia, with all its potential complications. Tension occurs mostly in patients with strictures or Barrett's esophagus, and is due to shortening of the esophagus from the inflammatory process (12-14).

\section{TECHNIQUES OF LAPAROSCOPIC GERD SURGERY}

Laparoscopic Nissen fundoplication: The Nissen fundoplication was the gold standard in traditional open GERD surgery and remains so in the minimally invasive version. It consists of a crural repair and a $360^{\circ}$ plication of the gastric fundus around the lower esophagus. The plication is 2 to $3 \mathrm{~cm}$ long (Figure 1). Both lower esophageal sphincter pressure and intra-abdominal length are augmented, and the angle of His is accentuated (15).

Laparoscopic Toupet procedure (posterior fundoplication): The Toupet procedure is a $270^{\circ}$ posterior wrap anchored to the repaired crura. It is the most widely used alternative when GERD is accompanied by problems of esophageal motility. It is also used as an antireflux procedure in the surgical treatment of achalasia by laparoscopic Heller myotomy (Figure 2).

Laparoscopic Dor procedure (anterior fundoplication): The Dor procedure is a partial anterior fundoplication. It is an alternative to the Toupet procedure for the same indications; however, most authors report a higher failure rate for long term control of reflux (Figure 3).

Laparoscopic Collis Nissen gastroplasty (esophageal lengthening procedure): The Collis Nissen gastroplasty uses the lesser curvature of the stomach to fashion a tube to elongate the esophagus and obtain the appropriate intraabdominal length. A partial or total fundoplication is added to the gastroplasty to obtain the antireflux function (Figure 4). 


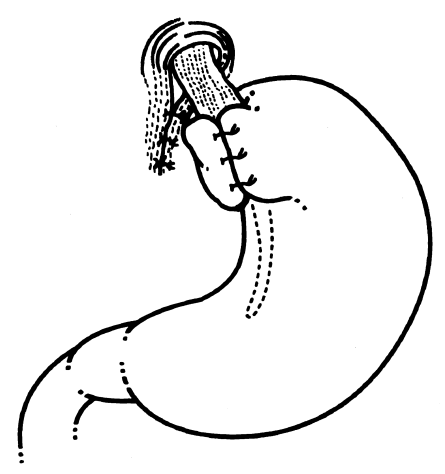

Figure 1) Laparoscopic Nissen fundoplication consisting of a $360^{\circ}$ plication of the gastric fundus around the lower esophagus. The plication usually measures 2 to $3 \mathrm{~cm}$

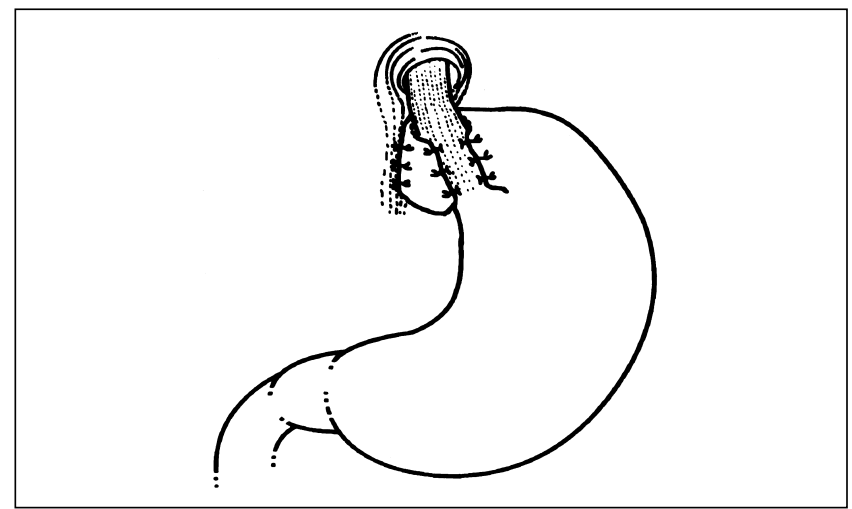

Figure 2) Laparoscopic Toupet procedure consisting of a $270^{\circ}$ posterior plication anchored to the repaired crura. This repair is mainly used when esophageal motility is altered

\section{LAPAROSCOPIC TECHNIQUE}

When a laparoscopic approach is used, the technical elements are the same as for an open abdominal procedure. The patient is admitted to the hospital on the morning of surgery.

Three $12 \mathrm{~mm}$ and two $5 \mathrm{~mm}$ ports are used. The left lobe of the liver is retracted towards the anterior abdominal wall and a mechanical arm keeps the retractor stable. A mechani$\mathrm{cal}$ arm is also used for the camera. The gastrohepatic omentum is opened in the pars flaccida, and the hiatus is dissected. The vagus nerves are identified and preserved, and the crura are approximated. An appropriate number of short gastric vessels are ligated to mobilize the fundus adequately and pass it behind the esophagus. Some authors do not consider ligating the short gastric vessels to be necessary and omit that step, in which case the fundoplication is created with the anterior part of the fundus rather than the posterior portion as in traditional Nissen repair (the Rosetti modification). A 2 to $3 \mathrm{~cm}$ plication is sutured anteriorly using two to three sutures. This is done over a calibration bougie (Figure 1).

The nasogastric tube is removed, usually in the recovery room. Meperidine is administered on the first night after surgery, and acetaminophen and nonsteroidal anti-inflammatory drugs are used thereafter unless contraindicated. Fluids

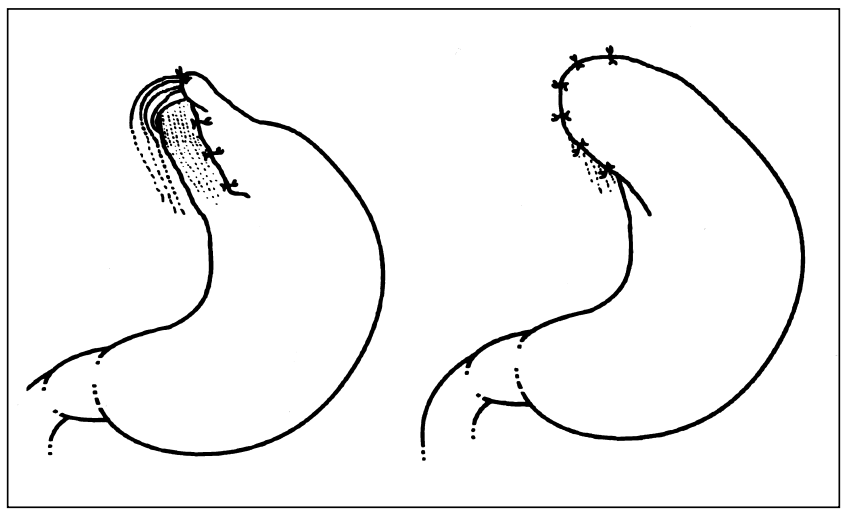

Figure 3) Laparoscopic Dor procedure consisting of a partial anterior fundoplication. This is an alternative to the Toupet procedure for the same indications, ie, mainly used when esophageal motility is altered

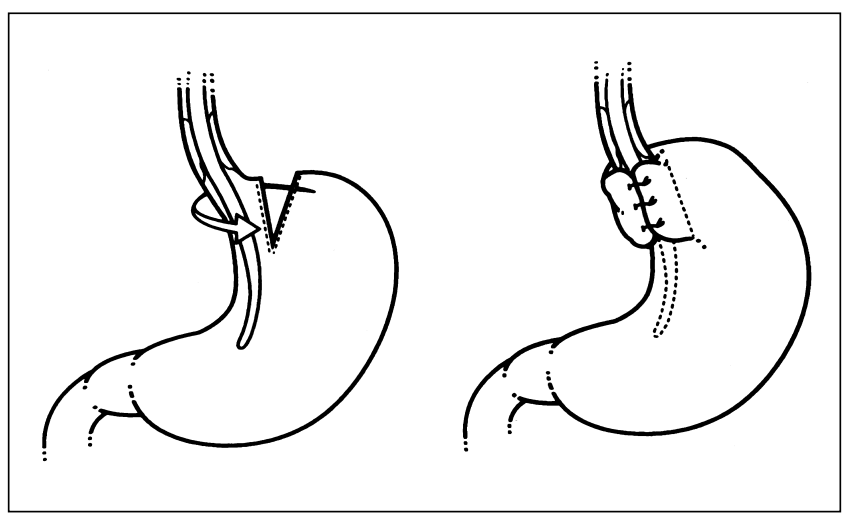

Figure 4) Laparoscopic Collis Nissen gastroplasty consisting of an esophageal lengthening procedure with a fundoplication. This procedure is used with a short esophagus

are started the next morning; if fluids are tolerated, the patient is instructed to increase his or her diet as tolerated. Discharge from the hospital usually occurs on the second or third postoperative day, except for very elderly or medically challenged patients.

\section{DIFFICULT HIATAL HERNIA REPAIR}

Correcting reflux laparoscopically sometimes can be technically demanding. Surgeons are always mindful of the surgical complications attending the laparoscopic correction of gastroesophageal reflux. More specifically, it should be remembered that bile duct trauma is to laparoscopic cholecystectomy as esophageal perforation and its potential consequences are to laparoscopic GERD surgery.

\section{DIFFICULTY FACTORS IN LAPAROSCOPIC HIATAL HERNIA REPAIR}

The following factors increase the likelihood of intraoperative mishap or the need to convert to an open procedure.

Obesity: The left lobe of the liver in obese patients can be difficult to retract safely. Producing liver lacerations or subcapsular hematomas is easy. In most series, a large left lobe of the liver is the most frequent cause of conversion to an open 
procedure. It is advised that laparoscopic fundoplication be limited to men who weigh less than $113 \mathrm{~kg}$ and women who weigh less than $91 \mathrm{~kg}(1)$.

Trauma (recognized or not) to the esophagus is more likely to occur in obese patients, usually during the creation of the retroesophageal window. It can be caused by inappropriate use of the cautery, retractors or other instruments, mostly in blind dissection of the posterior region of the esophagus. All dissection during laparoscopic Nissen fundoplication should be done under direct vision, especially in obese patients. In difficult cases, a $30^{\circ}$ or $45^{\circ}$ laparoscope can be useful to show the posterior aspect of the esophagus.

Transhiatal migration of the repair $(3 \%)$ is also thought to occur more frequently in obese patients if crural repair is inadequate or if the repair is not fixed to the right crux or the undersurface of the diaphragm. The phrenoesophageal epiphrenic fat pad should be used as a handle to manipulate the stomach and esophagus. Before the sutures for the fundoplication are placed, the fat pad is resected to eliminate tissue interposition between the esophagus and the repair, and possible dysphagia.

Previous abdominal surgery: The second most frequent cause of conversion to open surgery is adhesions from previous upper abdominal surgery. It is worthwhile to offer these patients laparoscopy, with the understanding that the conversion rate to the traditional approach is higher.

To avoid injury from insertion of the first trocar, an open approach should be used. A zero tolerance of first trocar injury should be the standard in all cases of laparoscopic surgery.

Adhesions should be incised close to the peritoneum because this is where the avascular areolar plane is situated. When no vessels are seen, sharp dissection should be used and the use of a cautery should be limited to areas where hemostasis is required. This approach limits surgical trauma. Usually, careful and deliberate dissection permits exposure of the operative field and allows the appropriate identification of all anatomical structures, allowing the laparoscopic procedure.

Previous antireflux surgery: Failure after GERD surgery requires careful assessment to decide the most likely cause of failure and the most appropriate course of action. Laparoscopic secondary corrective surgery is difficult, and the conversion rate to open surgery is high (more than $30 \%$ in most reports). Laparoscopic correction of recurrence is largely anecdotal. Nevertheless, the patient should be offered initial laparoscopic assessment, followed by the appropriate repair, whether laparoscopic or open. The patient should be informed that the corrective procedure will likely need to be done as an open procedure. If laparoscopy is to be successful, shortcuts cannot be used. All the pertinent anatomy needs to be completely dissected under direct vision for adequate correction.

Peptic strictures: Patients coming to surgery with peptic strictures often have had esophageal dilations as part of their medical management. At operation, the esophagus is often the site of a mixed acute and chronic inflammation pro-
TABLE 2

Indications for laparoscopic esophageal resection in gastroesophageal reflux disease

Undilatable strictures

Very long strictures that do not allow sufficient mobilization of the esophagus

Two or more failed antireflux procedures

Strong suspicion of malignancy or severe dysplasia

cess. The esophagus is larger in outside diameters because the inflammatory process involves the surrounding areolar tissue.

Laparoscopic manipulation and mobilization of the esophagus are more difficult, have a higher risk of hemorrhage or esophageal trauma, and may entail shortening of the esophagus, which must to be assessed and dealt with appropriately (16).

The short esophagus: In some cases of Barrett's esophagus and stricture, the esophagus is associated with significant esophageal shortening. Standard antireflux procedures are inappropriate and result in an unacceptably high failure rate (45\%), primarily because the esophagus cannot be mobilized sufficiently to achieve a 4 to $5 \mathrm{~cm}$ reduction of an intraabdominal segment of the esophagus, and the fundoplication is under tension. The Collis-Nissen operation provides good results in more than $80 \%$ of cases, whereas the Collis-Belsey procedure provides good results in $50 \%$ to $70 \%$ of cases. Both procedures achieve better results than a standard antireflux operation. These are essentially esophageal-sparing procedures in very complicated and advanced disease and avoid the need for an esophageal resection (Table 2). The CollisNissen procedure can be performed laparoscopically $(11,16)$. Paraesophageal or parahiatal hernia repair: Paraesophageal or parahiatal hernia repair requires time and patience because many important steps are necessary: a complete resection of the sac, mobilization of the entire esophagus at the hiatus, posterior closure of the crura, occasional reduction of gastric volvulus and arguably a Nissen fundoplication. Adding a fundoplication to paraesophageal hernia repair should be considered for at least three reasons. First, abnormal reflux as defined by $24 \mathrm{~h} \mathrm{pH}$ testing is present in many patients who have paraesophageal hernia ( $30 \%$ to $60 \%$ ). Second, a proper repair implies such a complete mobilization of the structures at the hiatus that, even if reflux was not already present preoperatively, it is likely to occur postoperatively (20\%). Third, a Nissen fundoplication can be used to anchor the gastroesophageal junction in the subdiaphragmatic position, making recurrence less likely (17).

\section{RESULTS}

Results of the laparoscopic treatment of GERD were reviewed recently at a consensus development conference. It was concluded that the "safety of laparoscopic treatment of GERD is comparable and rather favourable compared to the open method. In terms of efficacy, significant advantages of the endoscopic antireflux operations are less postoperative 
TABLE 3

Outcome comparison of laparoscopic with open gastroesophageal reflux disease surgery

\begin{tabular}{lcc}
\hline Outcome & Laparoscopic surgery & Open surgery \\
\hline Mortality & $0.2 \%$ & $0-1.4 \%$ \\
Conversion to open surgery & $5.8 \%$ & $\mathrm{~N} / \mathrm{A}$ \\
Splenic injury & $0.1 \%$ & $0-8.5 \%$ \\
Pulmonary complications & $2.4 \%$ & $1-6.5 \%$ \\
Wound complications & $0.9 \%$ & $2.5 \%$ \\
Gastroesophageal leaks & $1 \%$ & $2 \%$ \\
Satisfaction & $87-100 \%$ & $87-97 \%$ \\
\hline
\end{tabular}

NA Not applicable

pain, shorter hospital stay, and earlier return to normal activities and work. In general, laparoscopic antireflux surgery has advantages over open conventional procedures if performed by trained surgeons" (18).

In most reports, patients requiring surgery are investigated outside the hospital, come to the hospital in the morning of surgery and leave the morning of the second or third postoperative day. No limits are imposed on their level of postoperative activity other than those dictated by common sense, pain or fatigue. Most patients are expected to have

\section{REFERENCES}

1. Hunter JG, Trus LT, Branum GD, Waring PJ, Wood WC. A physiologic approach to laparoscopic fundoplication for gastroesophageal reflux disease. Ann Surg 1996;223:673-87.

2. Spechler SJ. VA Cooperative Study Group: Comparison of medical and surgical therapy for complicated gastroesophageal reflux disease. N Engl J Med 1992;26:786-92.

3. Patti MG, Arcerito M, Pellegrini CA, Mulvihill SJ, Tong J, Way LA. Minimally invasive surgery for gastroesophageal reflux disease. Am J Surg 1995;170:614-8.

4. Costantini M, Crookes PF, Bremner RM, et al. Value of physiologic assessment of foregut symptoms in a surgical practice. Surgery 1993;114:780-7.

5. DeMeester TR, Bonavina L, Iascone C, Courtney JV, Skinner DB. Chronic respiratory symptoms and occult gastroesophageal reflux. Ann Surg 1990;211:337-45.

6. Fuchs KH, DeMeester TR, Albertucci M. Specificity and sensitivity of objective diagnosis of gastroesophageal reflux disease. Surgery 1987;102:575-80.

7. Waring JP, Hunter JG, Oddsdottir M, et al. The preoperative evaluation of patients considered for laparoscopic antireflux surgery. Am J Gastroenterol 1995;90:35-8.

8. Hinder RA, Filipi CJ, Wetscher G, et al. Laparoscopic Nissen fundoplication is an effective treatment for gastroesophageal disease. Am Surg 1994;220:472-81.

9. DeMeester TR, Bonavina L, Albertucci M. Nissen fundoplication for gastroesophageal reflux disease. Evaluation of primary repair in 100 consecutive patients. Ann Surg 1986;204:9-20.

10. Perdikis G, Lund RJ, Hinder RA, et al. Esophageal manometry and 24-hr $\mathrm{pH}$ testing in the management of gastroesophageal reflux patients. Am J Surg 1997;174:634-8. some dysphagia secondary to edema around the surgical repair during the first month after surgery, and should be on a soft diet for that period. Physicians should refrain from performing endoscopy during that time. Afterward, the rate of late dysphagia requiring dilation should be in the range of $4 \%$, with most of these patients having had some degree of inflammatory stricture before surgery. In a review of 2453 cases, the recurrent reflux rate was $3.4 \%$. The reoperation rate for dysphagia or reflux was less than $1 \%$. The laparoscopic approach has had an impressive influence in the reduction of iatrogenic splenic injury that accompanied the traditional open approach. A reduction in pulmonary and wound complications also has been reported by most authors (Table 3) (19-21).

\section{CONCLUSIONS}

Laparoscopic correction of gastroesophageal reflux has become a spectacular alternative to the traditional open approach when surgery is indicated. Good results depend on patient selection and good operative technique. Although lower morbidity, shorter hospital stay and earlier return to normal activities are achieved by this technique, surgeons should pay special attention to eliminate the low incidence ( $1 \%$ to $2 \%$ ) of unrecognized intraoperative gastroesophageal trauma reported with either repair.

11. Swanstrom LL, Marcus DR, Galloway GQ. Laparoscopic Collis gastroplasty is the procedure of choice for the shortened esophagus. Am J Surg 1996;171:477-81.

12. Barlow AP, DeMeester TR, Ball CS, et al. The significance of the gastric secretory state in gastroesophageal reflux disease. Arch Surg 1989;124:937-40.

13. Hinder RA, Filipi CJ. The technique of laparoscopic Nissen fundoplication. Surg Laparosc Endosc 1992;2:265-72.

14. Lind JF, Duthie HL, Schlegal JR, et al. Motility of the gastric fundus. Am J Physiol 1961;201:197-201.

15. Dallemagne B. Laparoscopic Nissen fundoplication. Surg Laparosc Endosc 1991;1:138-43.

16. Mamazza J, Schlachta CM, Poulin EC. Surgery for peptic strictures. In: Marcon N, ed. Management of Esophageal Stenosis, Gastrointestinal Endoscopy Clinics of North America. Philadelphia: WB Saunders Company, 1998.

17. Casabella F, Sinanan M, Horgan S, Pellegrini CA. Systematic use of gastric fundoplication in laparoscopic repair of paraesophageal hernias. Am J Surg 1996;171:485-9.

18. Eypasch E, Neugehauer E, Fisher F, et al. Laparoscopic antireflux surgery for gastroesophageal reflux disease (GERD). Results of a consensus development conference. Surg Endosc 1997;11:413-26.

19. Urschel JD. Complications of antireflux surgery. Am J Surg 1993;166:68-70.

20. Perdikis G, Hinder RA, Lund RJ, Raiser F, Katada N. Laparoscopic Nissen fundoplication: Where do we stand? Surg Laparosc Endosc 1997;7:17-21.

21. Glise H, Hallerback B, Johansson B. Quality-of-life assessment in evaluation of laparoscopic Rosetti fundoplication. Surg Endosc 1995;9:183-89. 


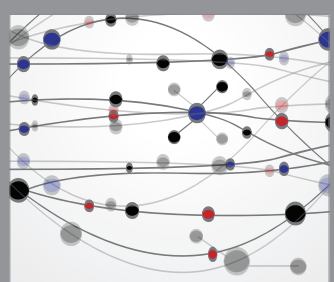

The Scientific World Journal
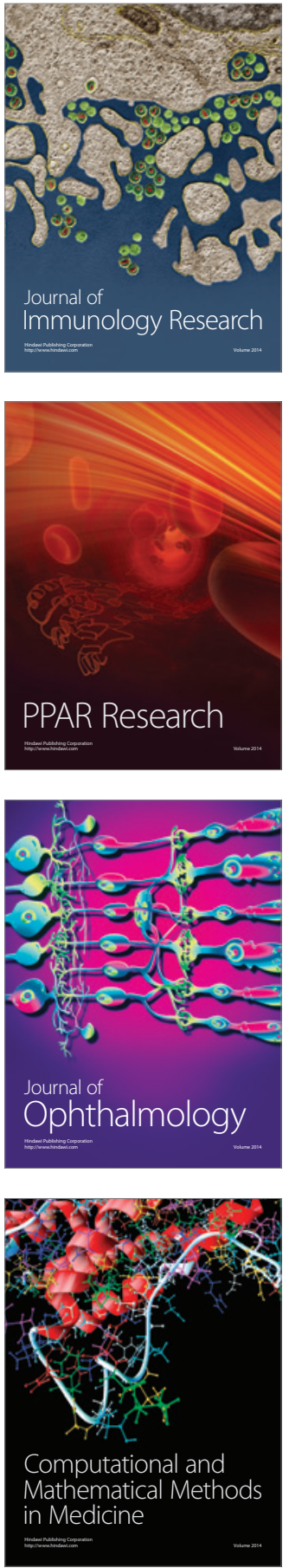

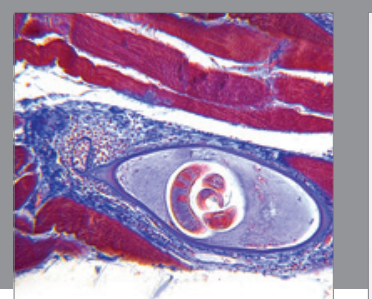

Gastroenterology Research and Practice

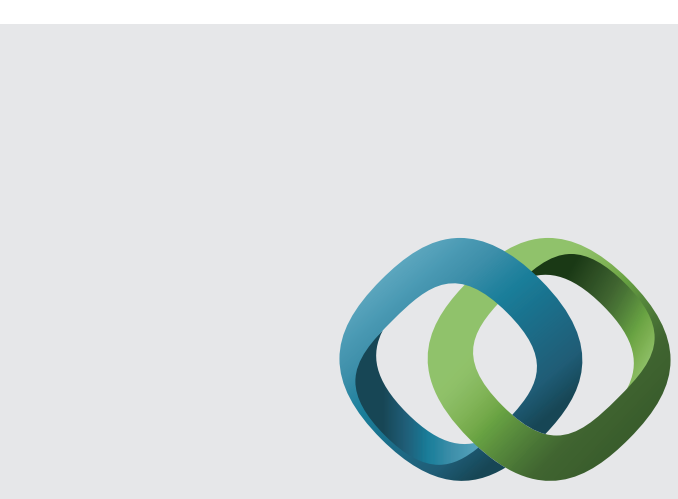

\section{Hindawi}

Submit your manuscripts at

http://www.hindawi.com
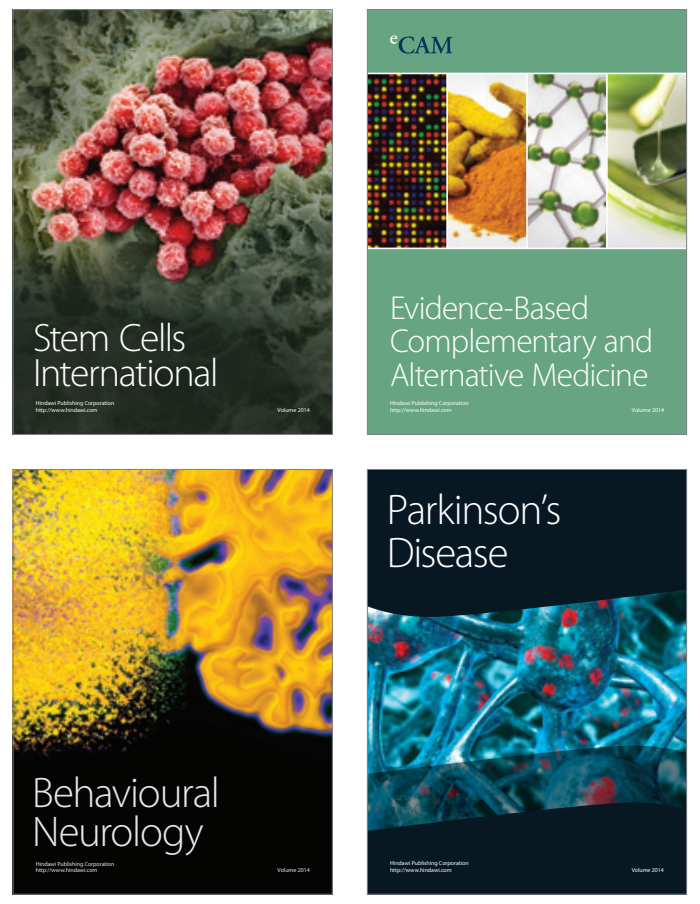
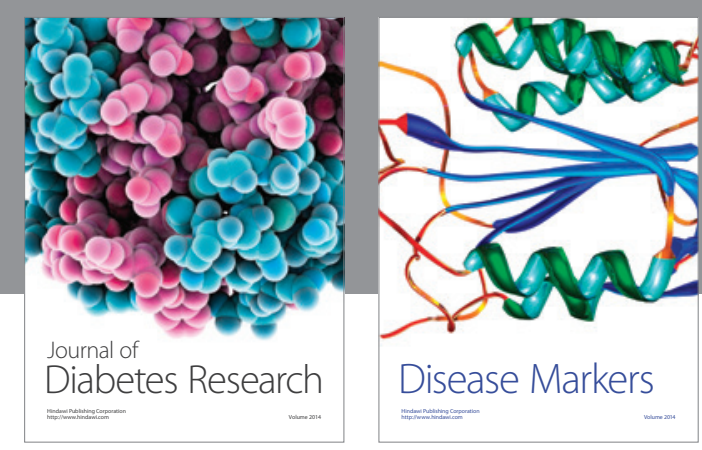

Disease Markers
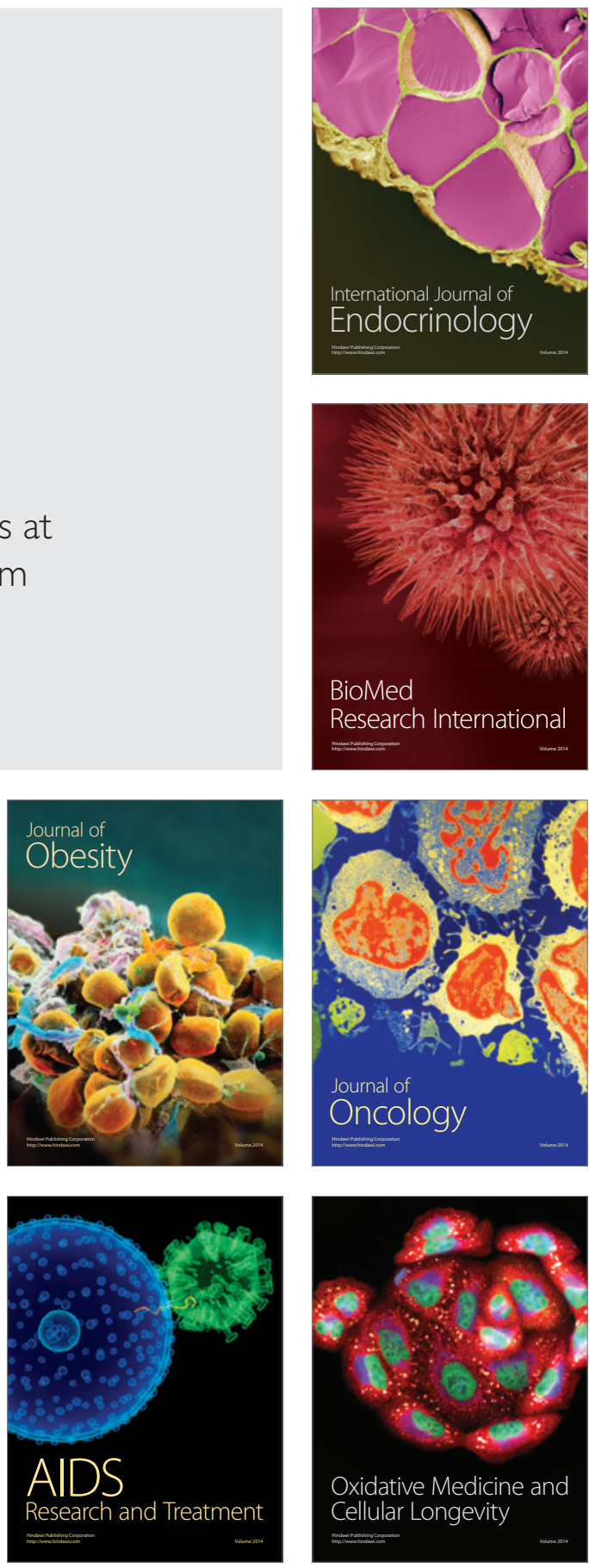